\title{
Childhood cancer in developing society: A roadmap of health care
}

Ramesh P. M.,

Marwaha R. K. ${ }^{1}$, Anish T. S. ${ }^{2}$

Department of Pediatrics, Govt. TD Medical College, Alappuzha, Kerala, 'Department of Pediatrics, Hematology Oncology Division, Post Graduate Institute of Medical Education and Research (PGIMER), Chandigarh, ${ }^{2}$ Department of Community Medicine, GMC, Thiruvananthapuram, Kerala, India

\author{
Address for correspondence: \\ Dr. Ramesh P. M., \\ Department of Pediatrics, Govt. \\ TD Medical College, Alappuzha, \\ Kerala, India. \\ E-mail: rpmpgi@gmail.com
}

\begin{abstract}
A B S T R A C T
Background: We assessed referral patterns of children with hematological malignancies $(\mathrm{HM})$ in North India. Materials and Methods: The parents/guardians were interviewed at presentation, in the period between October 2001 and November 2002. Patient delay (symptom-contact), health system delay (contact-diagnosis), total delay (symptomdiagnosis), and number of contacts were compared between high- and standard-risk disease group. Results: Of the 79 children (55 boys; 69.6\%) with HM, 47 (59.5\%) had Acute Lymphoblastic Leukemia (ALL). Forty-four children had high-risk disease. The patient, system and total delay were a median of 2 days (with Interquartile range IQR of $1-6)$, 37 days (IQR $13-55$ ), and 38 days (IQR 15-60) respectively. Majority of patients $(64 / 79 ; 81 \%)$ went to private sector (non governmental health care providers) for health care. Number of contacts, which was the most significant, correlate with system delay. Conclusions: Sensitizing the private sector practitioners about cancer in symptomatic children (pallor, bleeding, fever) may be effective.
\end{abstract}

Key words: Childhood cancer, epidemiology, patient delay, referral delay

\section{INTRODUCTION}

Estimated number of new cancers diagnosed in India every year is $700-900,000 .{ }^{[1]}$ The geographic, socioeconomic, health system inequalities in cancer treatment, in children, have only now begun to be addressed. ${ }^{[2]}$ Cancer remains the leading cause of death by disease in young individuals between 1 and 14 years of age. ${ }^{[3]}$

Advances in treatment in the past three decades have resulted in improved cure rates especially among children who are treated in a dedicated cancer care unit/center. ${ }^{[4,5]}$ Early diagnosis is fundamental. It allows timely treatment and prevents unnecessary complications. Delays in health care with adverse events along the cancer care continuum may negatively impact prognosis. Long delays in diagnosis may adversely affect prognosis. ${ }^{[0-9]}$ Previous studies have shown that time to diagnosis varies by cancer type, ranging from the shortest mean time to diagnosis of 2.5 weeks for renal tumors ${ }^{[10]}$ to the longest time, which is 29.3 weeks

\begin{tabular}{|l|l|}
\hline \multicolumn{3}{|c|}{ Access this article online } \\
\hline Quick Response Code: & Website: \\
\hline & www.ijmpo.org \\
\hline
\end{tabular}

for brain tumors. ${ }^{[11]}$ It has been reported that the time for patients to report to a health professional is longer than the time needed for referral to a specialist. ${ }^{[12]}$ Appropriate benchmarks for timely cancer care require a detailed understanding of the delays that may occur along the continuum of care. ${ }^{[13]}$

The Advanced Pediatric Centre, PGIMER, Chandigarh is a tertiary centre to which children from North and Western parts of the country are referred. Besides limitation in the existing health care systems, impact of delayed diagnosis on treatment initiation has not been quantified in our population.

\section{Research question}

What are the (probable) components for the delay in diagnosis of children (0-12 years) with hematological malignancies in developing countries like India?

\section{MATERIALS AND METHODS}

The parents/guardians of children with hematological malignancies (HM) were interviewed based on a predesigned performa at presentation in the period between the months of October 2001 and November 2002. Institutional ethics committee approval was obtained. Details available from previous prescriptions and referrals at hand were used in addition. Details of 
diagnosis (staging and risk categorization) were obtained from the case records maintained in the oncology clinic. HM included acute leukemia lymphocytic (ALL), myeloid (AML), undifferentiated (AUL)] and non-Hodgkin's lymphoma (NHL). Risk stratification of disease category at presentation (into high- and standard-risk disease) was as per pre-existing universally accepted criteria. Patient delay (symptom-contact interval), health system delay (contact- diagnosis interval), total delay (symptomdiagnosis interval), and number of contacts were recorded in Excel spreadsheet and compared. Categorical variables were compared using Mann-Whitney U-test (bivariate) and Kruskal-Wallis (multivariate) rank test.

\section{RESULTS}

Of the 79 children ( 55 boys; $69.6 \%$ ) with HM, the total number in high-risk category was 40 (50.6\%), rest were of the standard risk group. The mean age was $5.9 \pm 3.2$ years. The median patient delay of care seeking for children with high-risk $\mathrm{HM}$ was 2 (95\% CI: $1.27,3)$ days and for children with standard-risk HM was 3 (95\% CI: 1, 4.22) days $(P=0.42)$ [Table 1]. The median system delay of care providing for children with high-risk HM was 27 days and for children with standard risk HM was 40 days $(P=0.19)$. System delay was significantly more for children of farmers, those who approached alternative health care systems, those with more number of different contacts with health system [Table 1]. There was no significant difference in patient delay, health system delay, and total delay among other groups based on religion, socioeconomic status, education status of parents, urban residence. The median income of parents of children with $\mathrm{HM}$ in the study was Rs. 2500 (Rs 500-20,000). The median number of health care visits by parents of children with cancer was 3 (range 1-10), before they were evaluated at the tertiary cancer care centre. None of the children had any medical insurance. After multiple logistic regressions and adjusting for factors, the number of contacts was the significant factor associated with longer health system delay for care seeker, in case of children with hematological malignancy.

\section{DISCUSSION}

We undertook a survey to determine the probable factors contributing to a delay in the presentation of children to our cancer care centre. We studied delays as intervals in the path of healthcare of childhood cancer patients without implying any value in terms of clinical acceptability [Figure 1]. ${ }^{[13]}$ We examined trends for the overall combination of delay times that can be considered as part of the referral pattern, that is the time elapsed from first medical contact by the patient until the diagnosis / onset of treatment. Diagnosis delay for all patients was approximately 1.5 month.

In our study, age, sex and interval from onset of symptom to contact with health system had no significant impact on the referral pattern. In a study of prognostic factors of ALL in India ${ }^{[14]}$ investigators have observed that age, sex, and phenotype of the disease had no significant impact on treatment outcome. As in our study, the baseline demography reflects a care seeking behavior preferring male infants and young boys.

\begin{tabular}{|c|c|c|c|c|}
\hline Characteristic & Group & $n=79(\%)$ & $\begin{array}{l}\text { Patient delay } \\
\text { (in days) }\end{array}$ & $\begin{array}{l}\text { System delay } \\
\text { (in days) }\end{array}$ \\
\hline Sex* & Boys & $55(69.6)$ & $39 \cdot 3$ & 41.9 \\
\hline \multirow[t]{2}{*}{ Education of either parents* } & Illiterate & $19(24.1)$ & 43.6 & $35 \cdot 4$ \\
\hline & Literate & $60(75.9)$ & 38.9 & 41.5 \\
\hline \multirow[t]{3}{*}{ Residence } & Rural & $40(50.6)$ & 37.4 & $43 \cdot 5$ \\
\hline & Semiurban & $17(21.5)$ & $47 \cdot 3$ & 39.9 \\
\hline & Urban & $22(27.8)$ & 39.1 & 33.8 \\
\hline \multirow[t]{3}{*}{ Occupation } & Agriculture & $11(13.9)$ & 41.6 & $50.5(P=0.02)$ \\
\hline & Shopowner / business class / govt servants & $13(16.5)$ & 36.8 & 25.5 \\
\hline & Manual labourer - skilled/ unskilled & $55(69.6)$ & 40.4 & 41.3 \\
\hline \multirow[t]{3}{*}{ Religion } & Hindu & $22(27.8)$ & 41.5 & 43.6 \\
\hline & Muslim & $6(7.6)$ & 31.3 & 40 \\
\hline & Sikh & $51(64.6)$ & 40.4 & 38.4 \\
\hline \multirow[t]{3}{*}{ Source of first action } & Private allopath & $58(73.4)$ & 40.2 & 37.9 \\
\hline & Government health care & $15(19)$ & $39 \cdot 5$ & $39 \cdot 3$ \\
\hline & Alternative system of medicine & $6(7.6)$ & 39.6 & $61.8(P=0.05)$ \\
\hline \multirow[t]{2}{*}{ Risk category of cancer* } & Standard risk & $35(44 \cdot 3)$ & 41.8 & $46.7(P=0.02)$ \\
\hline & High risk & $44(55.7)$ & 38.6 & 34.7 \\
\hline
\end{tabular}

*-Signify 
Ramesh, et al.: Health seeking behaviour of children with cancer

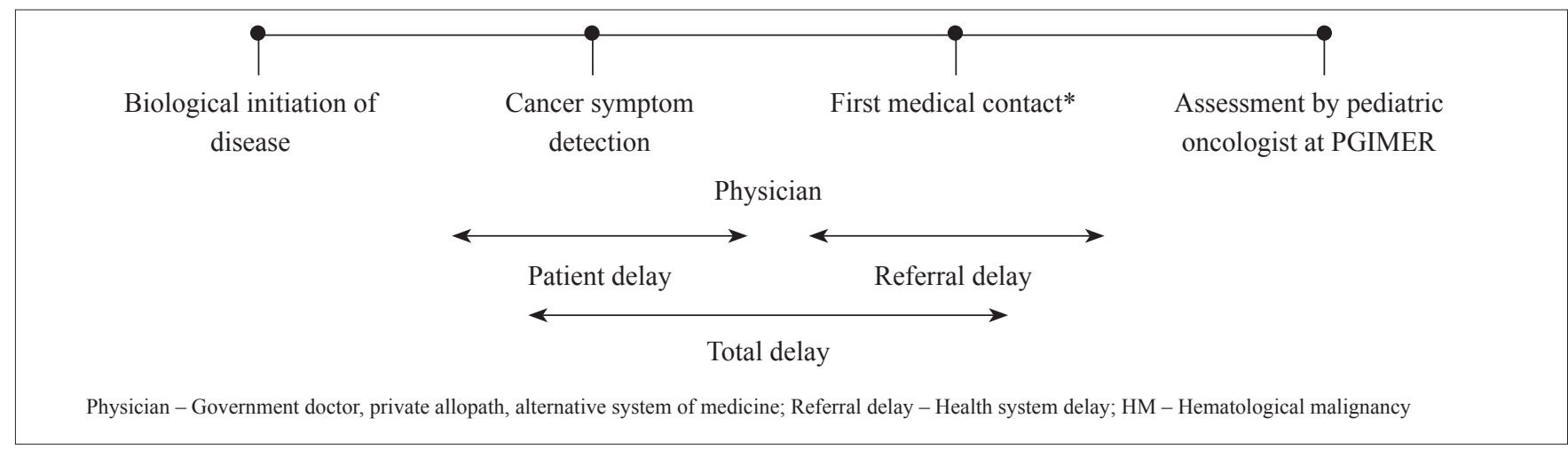

Figure 1: Components in pathway of care in childhood cancer (HM)

The median patient delay for care seeking was only 2 days. Among young children, one expects that close parental observation of the child might help the recognition of symptoms and signs, whereas among older children and adolescents the recognition of signs and symptoms may be more often initiated by the patients themselves. Although Klein-Geltink et al. ${ }^{[12]}$ reported that the patient delay is longer than the referral delay and that the patient delay is longer than the oncologist delay, ${ }^{[13]}$ in the 79 children with HM studied, health system or referral delay (time to referral to specialist) was found to be the longest time segment responsible for driving the overall length of the delays [Figure 1]. Referral delay was influenced by number and type of contacts. Parents who were farmers often cited reasons of time of sowing, harvesting, marketing, which contributed to the significant delay in care seeking for their children after the first contact. Children with standard risk disease had a longer health system delay than high-risk disease. As reported by Saha et al. ${ }^{[10]}$ also, tumor burden in young children with high risk disease may lead to faster progression of symptoms and therefore alert the health caregivers earlier. Often, physicians prescribed supportive care in the form of antipyretics, blood transfusionsm antibiotics, steroids with resultant delay in final diagnosis. Sensitizing the private sector practitioners about the possibility of hematological malignancy in symptomatic children (pallor, bleeding, fever) and the improved outcomes of care in a dedicated cancer care unit may be the most effective step in resource poor settings, for an early referral.

In India, the health system is designed to ensure that access to government medical services is provided to all citizens and paid for by public tax revenues without direct charges to the patient. Private health care system is also encouraged to supplement the public health delivery. People approach the private practitioners for health care first.

Limitations to this study: Firstly, its retrospective nature makes it difficult to ascertain the reliability and accuracy of the information collected. This may be particularly so for the reported initial onset of symptoms. The date information (primarily date of disease onset) was obtained from medical records and from patients or parents, which may have resulted in inaccurate recall. In conditions of poor referral systems, patients lose out on records in transit. However, we addressed it by the audits of prescription and referral slips and contacting referring physician whenever feasible at each centre within 24 hours of the patient's arrival at the hospital. Secondly, children with non-hematological malignancies were not included in this study, which would affect generalisability of our findings.

This study examines various delays from a regional perspective. Such studies across India may offer an opportunity to isolate the main time segment responsible for lengthening the cancer care pathway taken by children. This would enable evidence based decisions. Varying lengths of patient delay and referral delay, across settings, are the main contributors to delay in diagnosis. The information provided by a multicentric study, ${ }^{[15]}$ may assist the implementation of intervention programs, ${ }^{[3]}$ aimed at reducing delay where these can be most effective.

\section{REFERENCES}

1. Available from: http://www.icmr.nic.in/ncrp/bcifuture.pdf [last cited 2010 Jan 1].

2. Pui CH, Schrappe M, Masera G, Nachman J, Gadner H, Eden $\mathrm{OB}$, et al. Ponte di Legno Working Group: Statement on the right of children with leukemia to have full access to essential treatment and report on the Sixth International Childhood Acute Lymphoblastic Leukemia Workshop. Leukemia 2004; 18:1043-53.

3. Arceci R, Ettinger A, Forman E, Haase GM, Hammond GD, Hoffman $\mathrm{R}$, et al. National action plan for childhood cancer: Report of the national summit meetings on childhood cancer. CA Cancer J Clin 2002;52:377-9.

4. Pui CH, Cheng C, Leung W, Rai SN, Rivera GK, Sandlund JT, et al. Extended follow-up of longterm survivors of childhood acute lymphoblastic leukemia. N Engl J Med 2003;349:640-9.

5. Ribeiro RC, Pui $\mathrm{CH}$. Saving the children - improving childhood cancer treatment in developing countries. $\mathrm{N}$ Engl $\mathrm{J}$ Med 2005;352:2158-60. 
6. Reaman GH. A national approach to evaluating delays in diagnosis and treatment: Potential implications for age related and geo-political differences in access to care and outcome in children and adolescents with cancer. Pediatr Blood Cancer 2008;51:447-8.

7. Koivunen P, Rantala N, Hyrynkangas K, Jokinen K, Alho OP. The impact of patient and professional diagnostic delays on survival in pharyngeal cancer. Cancer 2001;92:2885-91.

8. Kowalski LP, Carvalho AL. Influence of time delay and clinical staging in the prognosis of head and neck cancer. Oral Oncol 2001;37:94-8.

9. de Camargo B, de Andrea ML, Franco EL. Catching up with history: Treatment of Wilms' tumour in a developing country. Med Pediatr Oncol 1987;15:270-6.

10. Saha V, Love S, Eden T, Micallef-Eynaud P, MacKinlay G. Determinants of symptom interval in childhood cancer. Arch Dis Child 1993;68:771-4.

11. Mehta V, Chapman A, McNeely PD, Walling S, Howes WJ. Latency between symptom onset and diagnosis of pediatric brain tumours: An Eastern Canadian geographic study. Neurosurgery 2002;51:365-72.

12. Klein-Geltink JE, Pogany LM, Barr RD, Greenberg ML, Mery
LS. Waiting times for cancer care in Canadian children: Impact of distance, clinical, and demographic factors. Pediatr Blood Cancer 2005;44:318-27.

13. Dang-Tan T, Trottier H, Mery LS, Morrison HI, Barr RD, Greenberg $\mathrm{ML}$, et al. Delays in diagnosis and treatment among children and adolescents with cancer in Canada. Pediatr Blood Cancer 2008;51:468-74.

14. Advani S, Pai S, Venzon D, Adde M, Kurkure PK, Nair CN, et al. Acute lymphoblastic leukemia in India: An analysis of prognostic factors using a single treatment regimen. Ann Oncol 1999;10:167-76.

15. Ribeiro RC, Steliarova-Foucher E, Magrath I, Lemerle J, Eden $\mathrm{T}$, Forget $\mathrm{C}$, et al. Baseline status of paediatric oncology care in ten low-income or mid-income countries receiving My Child Matters support: A descriptive study. Lancet Oncol 2008;9:721-9.

How to cite this article: Ramesh PM, Marwaha RK, Anish TS. Childhood cancer in developing society: A roadmap of health care. Indian J Med Paediatr Oncol 2011;32:30-3.

Source of Support: Nil, Conflict of Interest: None declared.

\section{New features on the journal's website}

Optimized content for mobile and hand-held devices

HTML pages have been optimized of mobile and other hand-held devices (such as iPad, Kindle, iPod) for faster browsing speed.

Click on [Mobile Full text] from Table of Contents page.

This is simple HTML version for faster download on mobiles (if viewed on desktop, it will be automatically redirected to full HTML version)

E-Pub for hand-held devices

EPUB is an open e-book standard recommended by The International Digital Publishing Forum which is designed for reflowable content i.e. the text display can be optimized for a particular display device.

Click on [EPub] from Table of Contents page.

There are various e-Pub readers such as for Windows: Digital Editions, OS X: Calibre/Bookworm, iPhone/iPod Touch/iPad: Stanza, and Linux: Calibre/Bookworm.

\section{E-Book for desktop}

One can also see the entire issue as printed here in a 'flip book' version on desktops.

Links are available from Current Issue as well as Archives pages.

Click on View as eBook 